\title{
Advances in bio-active constituents, pharmacology and clinical applications of rhubarb
}

\author{
Yu-Jie Cao ${ }^{1}$, Zong-Jin Pu ${ }^{1}$, Yu-Ping Tang ${ }^{1,2^{*}}{ }^{10}$, Juan Shen ${ }^{1}$, Yan-Yan Chen ${ }^{2}$, An Kang ${ }^{1}$, Gui-Sheng Zhou ${ }^{1}$ \\ and Jin-Ao Duan'
}

\begin{abstract}
Rhubarb is one of the most ancient, commonly used and important herbs in Chinese medicine. The modern researches of rhubarb clarified the efficacies, ingredients and mechanisms in a more scientific and rigorous way. The main chemical compositions of rhubarb include anthraquinones, anthrones, stilbenes, tannins, polysaccharides etc. These compositions show extensive pharmacological activities including regulating gastrointestinal, anticancer, antimicrobial, hepatoprotective, anti-inflammatory, protecting cardiovascular, cerebrovascular and so on. This paper reviews the recent studies on the active ingredients, pharmacological effects, clinical application and functional mechanism.
\end{abstract}

Keywords: Rhubarb, Ingredients, Pharmacological activities, Clinical application, Functional mechanism

\section{Background}

Rhubarb is a collective name of various perennial plants of the genus Rheum L. from Polygonaceae family. This plant has important economic value, not only referred to a few edible rhubarbs [1], but also used as purgative drug in China since the third millennium BC [2], firstly recorded in Shen Nong's Herbal Classic. Rhubarb has been suggested to exert eliminating heat, purging fire, cooling blood, dispersing blood stasis, dredging collateral antidotal and purgative effects, used to treat constipation, diabetic nephropathy, chronic renal failure, acute pancreatitis, gastrointestinal bleeding and other diseases [3].

There are articles summarizing the research progresses of rhubarb on treating acute organophosphorus pesticide poisoning [4], acute ischemic stroke [5], acute pancreatitis [6], chronic kidney disease [7] in recent years. Zheng [8] summarized the researches of rhubarb containing the isolation, pharmacological activities, and phytochemical

\footnotetext{
*Correspondence: yupingtang@njucm.edu.cn

${ }^{2}$ College of Pharmacy and Shaanxi Collaborative Innovation Center of Chinese Medicinal Resources Industrialization, Shaanxi University of Chinese Medicine, Xianyang 712046, China

Full list of author information is available at the end of the article
}

analysis. But there is no article to associate the different components of rhubarb with diseases. In this article, we not only introduce the active ingredients, pharmacology, applications and mechanism of rhubarb, but also summarize the relationship between ingredients and pharmacologic action.

\section{Chemical components}

Back in the early years of the nineteenth century, the chemical compositions of officinal rhubarb had been researched [3]. In recent years, unofficial rhubarbs with rich resources are also studied. Although they are different species, the main composition of these rhubarb species is similar. Scientists and medics isolated various types of compounds from rhubarb, containing anthraquinones and their glycosides, anthrones and their glycosides, stilbenes, butyrophenones and chromones, tannins, saccharides and so on [9].

\section{Anthraquinones}

Anthraquinones are the main characteristic as well as pharmacodynamic ingredients of rhubarb [10, 11]. The proportion of anthraquinones ranges from 3 to $5 \%$ in different species [3]. More than 30 anthraquinones have 
been isolated and identified from rhubarb [12]. They are divided into free type and combination type. Free anthraquinones mainly contain rhein, emodin, aloe-emodin, chrysophanol, physcion, isoemodin, chrysaron, isoemodin, laccaic acid D. Combination anthraquinones are the glycosides combined by free anthraquinones and glycosyl. There are many kinds of anthraquinone glycosides, containing aloe-emodin-8-glucoside, emodin-8-glucoside, rhein-8-glucoside, physcion diglucoside, emodin6 -glucoside etc. [3, 9]. Main structures of anthraquinones $(1-11)$ are as follows (Fig. 1) [3, 8, 12].

Rhein has the ability of protecting kidney [13], inhibiting the formation of renal fibrosis [14], improving diabetic nephropathy [15] and lipid disorders [16]. Rhein also has a strong inhibitory effect on common clinical anaerobes [17].

Emodin has a wide range of pharmacological effects, including anti-tumor [18], anti-microbial [19], antioxidant [20], anti-inflammatory [21]. It also can bring high blood pressure down, decrease blood lipids and improve microcirculation, protect liver and kidney [17].

Chrysophanol has a protective effect on the nervous system, improving the activity of antioxidant enzyme, reducing the damage of oxygen free radicals to cells [22].

Physcion also has neuroprotective effect, inhibiting the inflammatory response after cerebral ischemia and reducing the nerve damage caused by reperfusion [23]. Besides, physcion has anti-tumor effects on a variety of carcinoma cells, mainly through inhibiting cell proliferation, inducting apoptosis and blocking cell cycle [24].

Aloe-emodin, another important active compound of rhubarb, has attracted much attention, due to its various effects such as cardiovascular protection, hepatoprotective activities, anti-tumor, antibacterial, antifungal, antiviral, anti-inflammatory, immune regulation, laxative [17, 25].

Anthraquinone glycosides process the characteristic of antioxidant, anticancer, anti-inflammatory, laxative and many others biological properties [26], laxative activity strongest among them.

\section{Anthrones and dianthrone}

Anthrones and dianthrone, also characteristic components of rhubarb, are related to purgative activity. Mainly these include rheinosides $\mathrm{A}-\mathrm{D}$, palmidin $\mathrm{A}, \mathrm{B}, \mathrm{C}$, rheidin A, B, C, and sennosidin A-F, etc. [9]. 26 anthrones have been isolated from the species of this genus [8]. Sennosides have a strong cathartic effects though translating to anthraquinones in vivo. The main structures of anthrones and dianthrone (12-25) are as follows (Fig. 2) [3, 8, 12].

\section{Stilbenes}

Stilbenes are important components of rhubarb, concerning antihyperlipidemic, antioxidant and hepatoprotective effect $[3,27]$. So far, there are 31 compounds found in rhubarb belonging to stilbenes [12], such as rhapontigenin, isorhapontigenin and rhaponticin. Some representative<smiles>[R]c1c([R])c([R])c2c(c1[R])C(=O)c1c([R])c([R])c([R])c([R])c1C2=O</smiles>

$\begin{array}{ll}\mathbf{1} & \text { Rhein } \\ \mathbf{2} & \text { Emodin } \\ \mathbf{3} & \text { Chrysophanol } \\ \mathbf{4} & \text { Aloe emodin } \\ \mathbf{5} & \text { Physcion } \\ \mathbf{6} & \text { Isoemodin } \\ \mathbf{7} & \text { Laccaic acid D } \\ \mathbf{8} & \text { Aloe-emodin-8-oglucoside } \\ \mathbf{9} & \text { Chrysophanol-8-glucoside } \\ \mathbf{1 0} & \text { Physcion-8-glucoside } \\ \mathbf{1 1} & \text { Physcion diglucoside }\end{array}$

Fig. 1 Main structures of rhubarb anthraquinones

$\begin{array}{llllllll}\mathbf{R}_{1} & \mathbf{R}_{2} & \mathbf{R}_{3} & \mathbf{R}_{4} & \mathbf{R}_{5} & \mathbf{R}_{6} & \mathbf{R}_{7} & \mathbf{R}_{8} \\ \mathrm{H} & \mathrm{COOH} & \mathrm{H} & \mathrm{OH} & \mathrm{OH} & \mathrm{H} & \mathrm{H} & \mathrm{H} \\ \mathrm{H} & \mathrm{CH}_{3} & \mathrm{H} & \mathrm{OH} & \mathrm{OH} & \mathrm{H} & \mathrm{OH} & \mathrm{H} \\ \mathrm{H} & \mathrm{CH}_{3} & \mathrm{H} & \mathrm{OH} & \mathrm{OH} & \mathrm{H} & \mathrm{H} & \mathrm{H} \\ \mathrm{H} & \mathrm{CH}_{2} \mathrm{OH} & \mathrm{H} & \mathrm{OH} & \mathrm{OH} & \mathrm{H} & \mathrm{H} & \mathrm{H} \\ \mathrm{H} & \mathrm{CH}_{3} & \mathrm{H} & \mathrm{OH} & \mathrm{OH} & \mathrm{H} & \mathrm{OCH}_{3} & \mathrm{H} \\ \mathrm{H} & \mathrm{CH}_{3} & \mathrm{OH} & \mathrm{H} & \mathrm{OH} & \mathrm{H} & \mathrm{H} & \mathrm{OH} \\ \mathrm{H} & \mathrm{OH} & \mathrm{COOH} & \mathrm{CH}_{3} & \mathrm{OH} & \mathrm{H} & \mathrm{OH} & \mathrm{OH} \\ \mathrm{OH} & \mathrm{H} & \mathrm{H} & \mathrm{H} & \mathrm{H} & \mathrm{CH}_{2} \mathrm{OH} & \mathrm{H} & \mathrm{OGlu} \\ \mathrm{OH} & \mathrm{H} & \mathrm{CH}_{3} & \mathrm{H} & \mathrm{H} & \mathrm{H} & \mathrm{H} & \mathrm{OGlu} \\ \mathrm{OH} & \mathrm{H} & \mathrm{CH}_{3} & \mathrm{H} & \mathrm{H} & \mathrm{CH}_{3} & \mathrm{H} & \mathrm{OGlu}^{6} \\ \mathrm{OH} & \mathrm{H} & \mathrm{CH}_{3} & \mathrm{H} & \mathrm{H} & \mathrm{CH}_{3} & \mathrm{H} & \mathrm{OGlu}^{6} \rightarrow{ }^{1} \mathrm{Glu}\end{array}$


<smiles>[R10]Oc1cccc2c1C(=O)c1c(O)cc(C(=O)O)cc1C2([R4])[R4]</smiles>

$\begin{array}{lllll} & & \mathbf{R}_{\mathbf{1}} & \mathbf{R}_{\mathbf{2}} & \mathbf{R}_{\mathbf{3}} \\ \mathbf{1 2} & \text { Rheinoside A } & \text { Glu } & \text { Glu } & \text { OH } \\ \mathbf{1 3} & \text { Rheinoside B } & \text { Glu } & \text { OH } & \text { Glu } \\ \mathbf{1 4} & \text { Rheinoside C } & \text { Glu } & \text { Glu } & \text { H } \\ \mathbf{1 5} & \text { Rheinoside D } & \text { Glu } & \text { H } & \text { Glu }\end{array}$

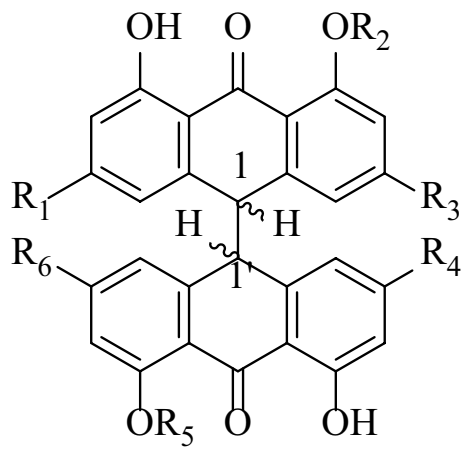

\begin{tabular}{|c|c|c|c|c|c|c|c|}
\hline & & $\mathbf{R}_{1}$ & $\mathbf{R}_{\mathbf{2}}$ & $\mathbf{R}_{\mathbf{3}}$ & $\mathbf{R}_{\mathbf{4}}$ & $\mathbf{R}_{\mathbf{5}}$ & $\mathbf{R}_{6}$ \\
\hline 16 & Palmidin A & $\mathrm{CH}_{2} \mathrm{OH}$ & $\mathrm{H}$ & $\mathrm{H}$ & $\mathrm{OH}$ & $\mathrm{H}$ & $\mathrm{CH}_{3}$ \\
\hline 17 & Palmidin B & $\mathrm{CH}_{2} \mathrm{OH}$ & $\mathrm{H}$ & $\mathrm{H}$ & $\mathrm{CH}_{3}$ & $\mathrm{H}$ & $\mathrm{H}$ \\
\hline 18 & Palmidin C & $\mathrm{CH}_{3}$ & $\mathrm{H}$ & $\mathrm{H}$ & $\mathrm{OH}$ & $\mathrm{H}$ & $\mathrm{CH}_{3}$ \\
\hline 19 & Rheidin A & $\mathrm{OH}$ & $\mathrm{H}$ & $\mathrm{CH}_{3}$ & $\mathrm{COOH}$ & $\mathrm{H}$ & $\mathrm{H}$ \\
\hline 20 & Rheidin B & $\mathrm{H}$ & $\mathrm{H}$ & $\mathrm{CH}_{3}$ & $\mathrm{COOH}$ & $\mathrm{H}$ & $\mathrm{H}$ \\
\hline 21 & Rheidin C & $\mathrm{H}$ & $\mathrm{H}$ & $\mathrm{CH}_{3}$ & $\mathrm{COOH}$ & $\mathrm{H}$ & $\mathrm{OCH}_{3}$ \\
\hline 22 & Sennosidin A & $\mathrm{COOH}$ & $\mathrm{H}$ & $\mathrm{H}$ & $\mathrm{COOH}$ & $\mathrm{H}$ & $\mathrm{H}$ \\
\hline 23 & Sennosidin C & $\mathrm{COOH}$ & $\mathrm{H}$ & $\mathrm{H}$ & $\mathrm{CH}_{2} \mathrm{OH}$ & $\mathrm{H}$ & $\mathrm{H}$ \\
\hline 24 & Sennoside A & $\mathrm{COOH}$ & Glu 1-1'trans & $\mathrm{H}$ & $\mathrm{COOH}$ & Glu 1-1'trans & $\mathrm{H}$ \\
\hline 25 & Sennoside C & $\mathrm{COOH}$ & Glu 1-1'meso & $\mathrm{H}$ & $\mathrm{COOH}$ & Glu 1-1'meso & $\mathrm{H}$ \\
\hline
\end{tabular}

Fig. 2 Main structures of rhubarb anthrones and dianthrones

structures of stilbenes (26-28) are showed at Fig. 3 [3, 8, 12].

\section{Tannins}

Since the 1880s, the discovery that rhubarb tannins reduced the content of BUN, sparked great interest and attention of scholars both at home and abroad. Tannins in rhubarb generally account for $10-30 \%$ [28]. It can be divided into hydrolytic type and condensation type. Gallic acid and d-cate-chin are the monomers of these tannins. Studies have discovered that tannins are the active elements owing to the stypticity and constipate activity of rhubarb [29]. It has been proved that tannins can adjust genotoxicity, oxidative stress, inflammation and apoptosis [30]. Total 
<smiles>[R]c1cc(/C=C/c2cc([R3])c([R4])c(O)c2)cc([R])c1[R]</smiles>

26 Rhaponticin

27 Piceatannol 3'-O-glucopyranoside

28 Resveratroloside<smiles>[R2]C1Cc2c(O)cc(O)cc2O[C@H]1c1ccc(O)c(O)c1</smiles>

$\begin{array}{lllll}\mathbf{R}_{\mathbf{1}} & \mathbf{R}_{\mathbf{2}} & \mathbf{R}_{\mathbf{3}} & \mathbf{R}_{\mathbf{4}} & \mathbf{R}_{\mathbf{5}} \\ \mathrm{OH} & \mathrm{H} & \mathrm{OH} & \mathrm{OCH}_{3} & \mathrm{H} \\ \mathrm{H} & \mathrm{OH} & \mathrm{OGlu} & \mathrm{H} & \mathrm{OH} \\ \mathrm{H} & \text { OGlu } & \mathrm{H} & \mathrm{H} & \mathrm{OH}\end{array}$

$\begin{array}{llllllll} & & \mathbf{R}_{\mathbf{1}} & \mathbf{R}_{\mathbf{2}} & & & \mathbf{R}_{\mathbf{1}} & \mathbf{R}_{\mathbf{2}} \\ \mathbf{2 9} & \text { (+)-Catechin } & \mathrm{H} & \mathrm{OH} & \mathbf{3 1} & \text { Gallic acid } & \mathrm{OH} & \mathrm{H} \\ \mathbf{3 0} & \text { (-)-Epicatechin } & \mathrm{OH} & \mathrm{H} & \mathbf{3 2} & \text { 4-O-methyl gallic acid } & \mathrm{OCH}_{3} & \mathrm{H} \\ & & & \mathbf{3 3} & \text { Glucogallin } & \mathrm{OH} & \text { Glu }\end{array}$<smiles>CC(=O)CCc1ccc(OCC(OC(=O)c2cc(O)c(O)c(O)c2)C(CO)CO)cc1</smiles>

Lindleyin

34

Fig. 3 Main structures of rhubarb stilbenes, tannins, butyrophenones and chromones

tannins extract can protect the kidney of $\mathrm{K}_{2} \mathrm{Cr}_{2} \mathrm{O}_{7}$-injured rats by treating $\mathrm{CrNT}$ as a free radical scavenger [31]. The basic structures of tannins (29-33) recorded at Fig. 3.

\section{Butyrophenones and chromones}

6 butyrophenones and 14 chromones have been isolated from rhubarb already. Lindleyin and Isolindleyin whose structures are showed at Fig. 3, have been confirmed possessing anti-inflammatory and analgesic activity [32]. Chromones are of expanding coronary vessels, decreasing blood pressure, removing cholesterol, antibacterial and other activities [3]. 


\section{Polysaccharides}

Polysaccharides play multiple roles and have extensive bioactivities in life process, with an immense potential in healthcare, food and cosmetic industries, due to their therapeutic effects and relatively low toxicity [33]. It has been proved that rhubarb polysaccharides have the following pharmacological activity, lowering the blood sugar, protecting liver, promoting the proliferation of intestinal epithelial cell, antineoplastic, anti-senescence and etc. [34].

We list the main active ingredient groups, representative component and mainly pharmacological activity, showing the relationship between these components and effects. Rhubarb contains several different active ingredients. Each active ingredient often has different pharmacological activities, acting on multiple targets. One pharmacological activity may also be caused by a variety of ingredients. There is a synergistic effect among these components. The relationship is summarized in Fig. 4.

\section{Pharmacology \\ Digestive system \\ Purgative}

Rhubarb has been used as a first-choice herb for constipation in clinic for thousands of years in China. Its purgative activity is definite. Processing can change the potency and efficacy of Chinese herb. The purgative activity is different in raw rhubarb and its processed products [35].

Active ingredients and mechanism of purgation: Combination anthraquinones, including sennosides, rheinosides and anthraquinone aglyconesa, are considered as the main bioactive constituents of the laxative effect $[26,36]$, playing the most important role in stimulating the intestine and leading to diarrhea [37]. Combined anthraquinone is metabolized into free metabolise in intestinal canal to exerting laxative effect [38]. Sennoside A, the strongest purgative composition, is rarely absorbed in the intestine, most of them reached the colon, metabolized into rhein anthrone and rhein in the intestine [39]. After giving chloramphenicol, the active of Escherichia coli restrained, the purging effect of sennoside $\mathrm{A}$ and $\mathrm{C}$ weaken, anthrone in the colon is also greatly reduced [40]. When the free anthraquinone derivatives were injected to the colon of rat, the re-absorption of water and electrolyte would be inhibited, resulted in diarrhea [41]. Most of free anthraquinones are absorbed before arriving colon. Therefore, combined anthraquinones play drastic effect by means of metabolizing into free anthraquinones. It is thought that anthraquinones can stimulate the nerve plexus within the mucosa and intestinal smooth muscles, promoting peristalsis [9]. The rhubarb extractives and the anthraquinone derivatives can antagonize the adrenaline effectively, which can inhibit the contraction of the smooth muscle in vitro system of isolated intestine [37]. It also regulates the colon cholinergic neuron of constipating rats [42]. Besides, Rhubarb effectively down-regulates the expression of $\mathrm{AQ} 4 \mathrm{P}$ in rat's proximal colon, and rhein/emodin can suppress the AQ4P expression of LoVo cells in vitro [43]. Sennoside A may decrease AQP3 expression in the colon to inhibit water transport from the luminal to the vascular side, leading to laxation [39]. The mechanism of its purgative activity is summarized as Fig. 5 [3, 9, 38, 44, 45].

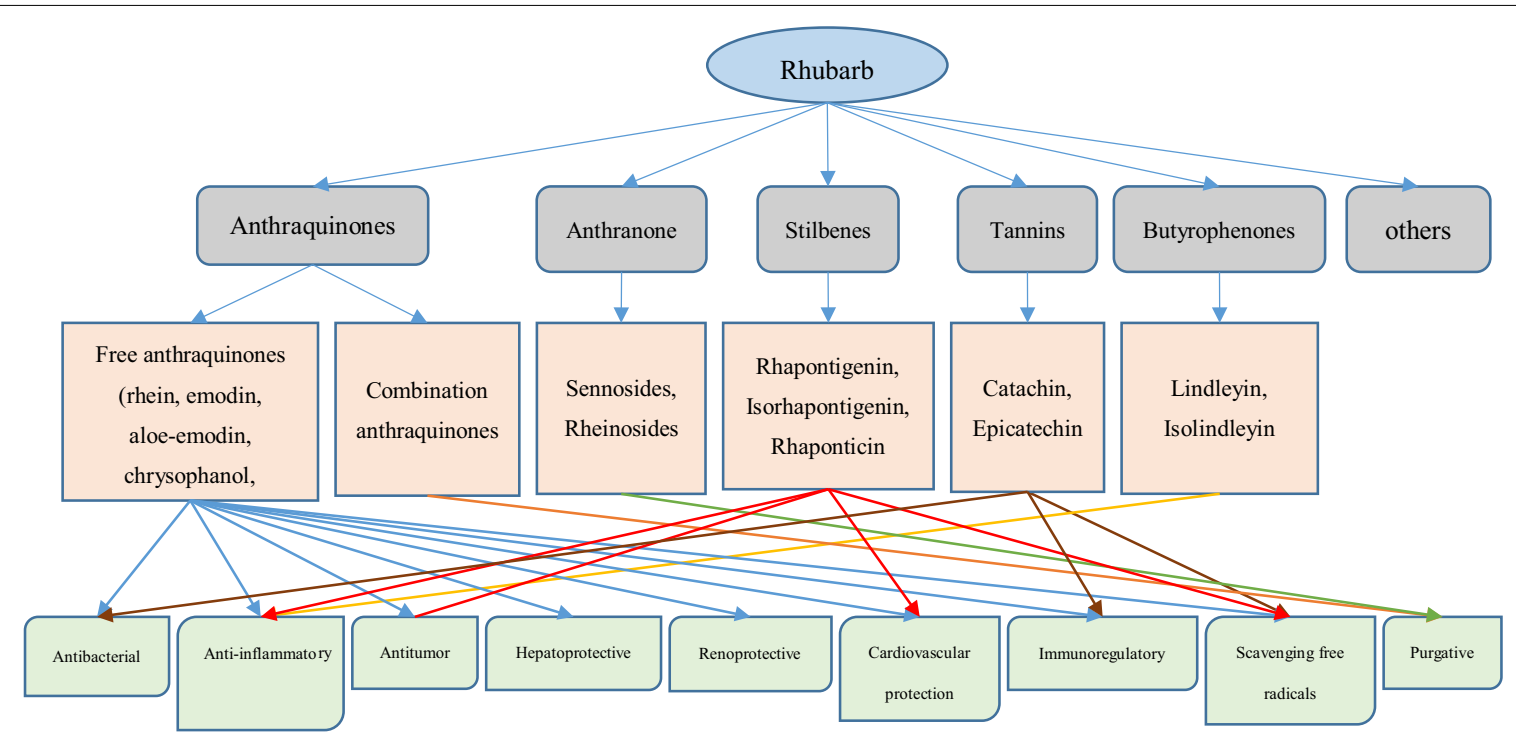

Fig. 4 Relationship between ingredients and efficacy of rhubarb 


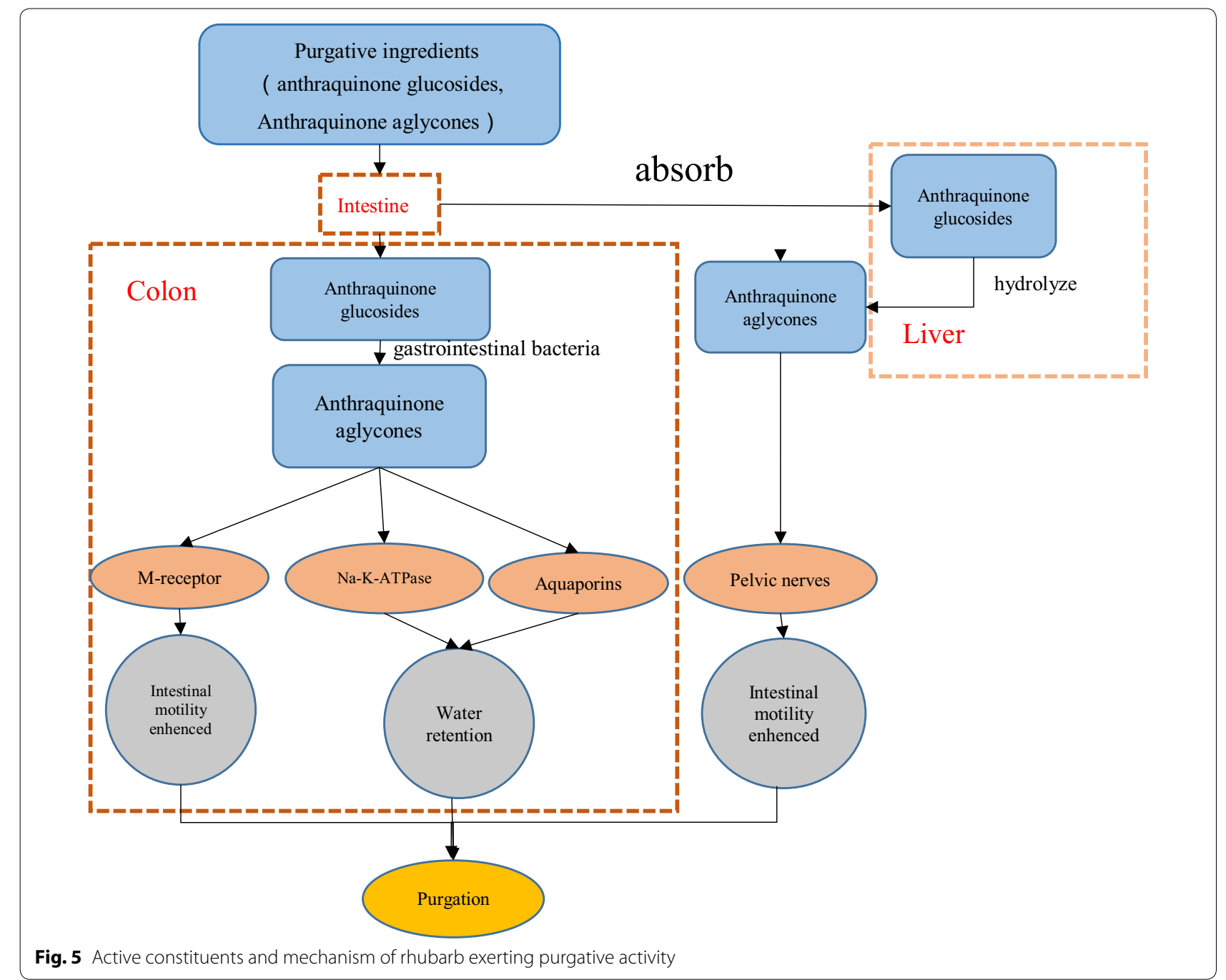

\section{Hepatoprotective}

Liver-protective function is an important part of studies on rhubarb in recent years. Rhubarb anthraquinones and tannins have a biphasic effect on liver, protection and damage. Anthraquinones showed stronger improvement on liver fibrosis and liver cell injury than tannins, and high dose tannins may injury liver in some extent [46]. Rhubarb and its free anthraquinones are also investigated in hepatic encephalopathy [47], liver fibrosis [48, 49], intrahepatic cholestasis [50] and so on.

\section{Cardiovascular system}

\section{Promoting blood circulation and hemostasis}

Rhubarb not only processes the effect of hemostasis but also improves hemorheology, stopping bleeding without leaving congestion. Charred rhubarb significantly improved the plasma viscosity, hematocrit, FIB, PT,
APTT and TT in the acute blood stasis rats [51], owning the best effect.

Mechanism of promoting blood circulation and Hemostasis: It is confirmed that chrysophanol and tannin are associated with the hemostasis effect. Chrysophanol can short the time of clotting, increase the number of platelets, promote blood coagulation in mice and tannin has a convergence effect, to promote local vasoconstriction [52]. Zhang found the main hemostasis mechanism of micron rhubarb charcoal was to produce prothrombin and thrombin by activating both endogenous and exogenous blood coagulation factor [53]. It is also believed that the pharmacological basis of promoting blood circulation is inhibiting the activity of $\mathrm{Na}^{+}-\mathrm{K}^{+}$-ATPase, to increase the plasma osmotic pressure, leading the water in the organization transferring into the blood vessels, increasing blood volume, helping with relieving microcirculation disturbance [54]. 


\section{Hypolipidemic}

Rhubarb has the effect of preventing and treating high blood lipids, reducing the TC, LDL, TG levels caused by high fat diet [55]. Rhubarb polysaccharide can reduce the blood lipid of diabetic atherosclerosis rats [56]. It has been confirmed that rhein and rheum emodin can regulate blood lipids, inhibit the formation of hyperlipidemia, prevent atherosclerosis [56, 57].

Mechanism of hypolipidemic: It promotes the excretion of cholesterol, improves blood rheology characteristics, decreases the release of inflammatory factors to maintain the balance of fat metabolism, inhibits the synthesis of cholesterol and triglyceride to achieve the purpose of regulating blood lipids [58]. Chen [59] found chrysophanol can reduce the blood lipid levels of zebrafish after high-fat diet, the mechanism may reduce the absorption of lipids in intestinal tract.

\section{Urinary system Kidney protection}

Kidney protecting effect of rhubarb is owing to the combination of various pharmacological activities itself. Rhubarb, with anti-bacterial, anti-inflammatory, enhancing immunization, diuretic, regulating metabolism and other effects, protects the damaged kidney tissue, promotes protein synthesis, speeds up the excretion of waste and so on [3]. Rhubarb is commonly used in clinical practice to treat kidney disease such as chronic functional failure and diabetic nephropathy.

Mechanism of kidney protection: In recent years, the renal protective effect of rhubarb [60] and its active components, especially emodin [61] and rhein [62, 63], have raised widespread concern. But generally accepted views on the therapeutical mechanism have not been attained [64]. Rhein has the effect of improving the metabolism of glycolipid, reducing the excretion of urinary protein and anti-oxidative stress, which may be one of the mechanisms to prevent and treat diabetic nephropathy [65]. Emodin mainly involves cells and cytokines, such as TGF- $\beta$, CTGF, MCP-1, and TSP- 1 to achieve the purpose of treating kidney diseases [66].

\section{Nervous system}

Rhubarb exerts an antipyretic effect by acting on the central nervous system. The mechanism of rhubarb antipyretic effect may be related to deduct the production of $\mathrm{PGE}_{2}$ and cAMP in hypothalamus and down-regulate central body temperature [67]. Chrysophanol improved the learning and memory function of cerebral ischemiareperfusion injured mice, increasing its anoxia tolerance capability, repairing the damage of brain tissue pathomorphism, so as to protect brain [68]. Besides the central nervous system, rhubarb also acts on the peripheral nervous system. It can improve the cholinergic nerve decreasing caused by constipation in colonic myenteric plexus [42]. Chrysophanol and physcion significantly improved the activity of hypoxia-injured cells, enhanced cell survival rate, protected and improved the ultrastructure of hypoxia-induced neurons [69].

\section{Respiratory system}

Rhubarb is also used to treat acute respiratory distress syndrome in clinic. Rhubarb, combining with Shenfu injection, can improve the condition of patients with acute respiratory distress syndrome, such as improving organ dysfunction and respiratory mechanics index, increasing the oxygenation index, shortening mechanical ventilation time [70]. Rhubarb also has a good therapeutic effect on respiratory failure caused by other diseases.

\section{Others}

\section{Anti-inflammatory}

Rhubarb has the effect of heat-clearing and detoxifying for its anti-inflammatory effects, used to treat inflammations caused by a variety of reasons. Rhubarb remitted the degree of auricular swelling and foot swelling in mice and rats, reduced total protein and LTB4 in airbag synovitis exudates [71].

Mechanism of anti-inflammatory: Currently, studies of rhubarb anti-inflammatory mechanism are focused on its monomer components such as emodin, rhein and aloe-emodin. Eodin can reduce the level of IL-6 in periodontal tissue of periodontitis rats [72]. Due to intervention effect of emodin lipid nano-microbubble, the protein expressions of p-P38, p-ERK, p-JNK and the release levels of inflammation cytokine, such as TNF- $\alpha$, IL-1 $\beta$, IL-6, were significantly decreased [73]. Rhein reduced the level of inflammatory factors caused by type II diabetes mellitus [74]. Hu [75] found aloe-emodin was also the bioactive component of rhubarb related to anti-inflammatory effect. Aloe-emodin could decrease the production of proinflammatory cytokine in LPS-induced RAW264.7 macrophages by inhibiting NF-kB, MAPK, and PI3K pathways.

\section{Antitumor}

A number of studies have shown that the anthraquinones of rhubarb could inhibit the growth and proliferation of various cancer cells [8]. Its extract and active monomers including aloe-emodin, emodin and rhein, are researched on multiple cancer models [76-78].

Mechanism of antitumor: to determine and identify the possible molecular mechanisms of anti-cancer effect of rhubarb, medical practitioners focused on the free anthraquinones of rhubarb and emodin is the most frequently studied element among the active constituents. 
Firstly, emodin inhibited the proliferation of tumor cell and induced apoptosis. Liu [79] found emodin inhibit the growth of human pancreatic cancer cell line Panc1 , and this inhibition effect was obvious connected with concentration and time. Secondly, it could inhibit the growth of tumor blood vessels. He [80] investigated the $95 \%$ ethanol extract and four subsequent fractions of rhubarb root and five anthraquinones extract on zebrafish model by quantitative endogenous alkaline phosphatase assay and staining assay, finding the anthraquinones with acidic or polar, hydrophilic substitution at C- 6 or C-3 positions, played a substantial role in inhibiting angiogenesis. Then, rhubarb inhibited carcinoma cell metastasis. Tsai found rhubarb extract inhibit HA22T cell migration in wound healing in a dosedependent manner [81].

\section{Anti-bacterial}

It has been confirmed that anthraquinone derivatives of rhubarb have remarkable antibacterial activity on several experimental bacterial strains in vitro [82, 83]. Staphylococcus aureus are often used on experiment because it is sensitive to rhubarb. Zhou [84] proposed rhubarb exerted antibacterial activity by changing the membrane permeability, inhibiting the synthesis of proteins and respiratory metabolism. Liu investigated on Emodin's effect and mechanisms on anti-MRSA in vitro and vivo, discovering that Emodin can destroy the cytoderm and cytomembrane structure of methicillin-resistant Staphylococcus aureus [85].

\section{Anti-fibrosis}

Many studies showed that rhubarb and its active components principally refer to emodin and rhein, could ameliorate organ fibrosis including renal, liver, lung, pancreas, cardiovascular system and so on $[86,87]$.

Mechanism of anti-fibrosis: Xu [88] summarized the mechanism for rhein ameliorating renal fibrosis as follows: inhibiting the infiltration of inflammatory cell, the transdifferentiating of renal tubular epithelial cells, the expression of profibrotic cytokines and blocking the activation of interstitial fibroblast. Wang [49] investigated the inhibitory effect and possible mechanism of emodin on hepatic fibrosis caused by $\mathrm{CCl}_{4}$, finding that emodin exerted anti-hepatic fibrosis effect for inhibiting the activation of hepatic stellate cell though up-regulation the expression of Smad7 and down-regulation the expression of $\alpha$-SMA in liver tissue. Liu [87] observed the influence of emodin on bleomycin-induced pulmonary fibrosis in rats, explored its protective mechanisms, proposing emodin may protect against rats with pulmonary fibrosis by enhancing antioxidation and antiinflammatory ability.

\section{Application}

With the deep research on rhubarb, a traditional diarrhea drugs, its clinical application is widened, not only used to treat the constipation, but also other diseases.

\section{Constipation}

Rhubarb has a significant diarrhea effect, used to treat constipation caused by various reasons on clinic [89-91]. $\mathrm{Yu}$ found that umbilicus compressing of Rhubarb and Mirabilite achieved satisfactory and safe efficacy on constipation patients with orthopedic surgery by observing their bristol stool scale, defecation frequency and total effective rate [92]. Clinically, rhubarb often plays a curative effect through acupoint application rather than oral administration.

\section{Diabetic nephropathy and chronic renal failure}

Rhubarb is one of the most popular traditional Chinese herbs used in treating diabetic nephropathy (DN) and chronic renal failure (CRF) [93].

A large number of related literatures reported that rhubarb was often used in conjunction with other drugs in the treatment of diabetic nephropathy. Liu [94] found the SCr, BUN, Alb and FBG significantly improved after the patients treated with rhubarb compound. Rhubarb could improve the condition of diabetic nephropathy patients by reducing the excretion of urinary protein, lowering blood lipid, improving renal function, regulating the abnormal expression of TGF- $\beta 1$, MMP-2, MMP-9 and MCP-1 in the blood of diabetic nephropathy patients, inhibiting renal inflammation and fibrosis process [95].

Rhubarb soda tablets combined with Jinshuibao Capsule significantly reduced Scr and BUN levels in patients with chronic renal failure [96]. Xiao [97] summarized the clinical and laboratory study on the rhubarb in the treatment of CRF. He found rhubarb and its prescriptions had a definite curative effect on CRF by ameliorating azotemia, preventing nephritic compensatory hypertrophy and high metabolism situation, and so on.

\section{Acute pancreatitis}

Rhubarb can promote the secretion and discharge of pancreatic juice, increase pancreatic juice flow. It is used to treat acute edema and hemorrhagic necrotizing pancreatitis [6].

Rhubarb and mirabilite external application reduced the risk of abdominal distension and stomachache, reducing the probability of complications in patients with acute pancreatitis. The relevant laboratory indicators were closer to normal and the average hospital stay was significantly shorter [98].

Rhubarb inhibited the inflammatory response, improved intestinal microcirculation and restored 
normal intestinal absorption, to exert the function of treating AP [99]. The free anthraquinone of rhubarb and the rhubarb decoction could attenuate kidney injury induced by acute pancreatitis [100].

\section{Gastrointestinal bleeding}

Rhubarb has hemostatic effect, used to treat gastrointestinal bleeding clinically. Conventional treatment combined with rhubarb powder exerting better therapeutic effect on the upper gastrointestinal bleeding by comparing control group and observation group [101]. Tan found rhubarb reduced curative time and increased the recovery rate of gastrointestinal bleeding caused by severe brain injury [102].

\section{Others}

In addition to the above diseases, rhubarb is also used to treat a variety of liver and kidney diseases, gastrointestinal dysfunction, cancers, hemorrhoid, periodontitis and so on [3].

\section{Toxicity}

It has been confirmed that rhubarb has varying degrees of toxicity on liver, kidney, gastrointestinal tract, reproductive system and blood systems, may possess teratogenicity and reproductive toxicity [103]. It is thought that gastrointestinal tract, liver, kidney are potential target organs of its toxicity.

Gastrointestinal toxicity of rhubarb characterized by diarrhea, constipation and melanosis [104]. Anthraquinones in rhubarb have purgative effect, while tannic acid and other components causing diarrhea. Small doses of rhubarb did not cause diarrhea, on the contrary inducing secondary constipation after discontinuation [26].

Yan [105] administrated total rhubarb anthraquinones on S.D. rats for 13 weeks to induce nephrotoxicity, finding the renal tubule epithelial cells swelled and denatured in tissue slice. Da [106] compared the toxicity of rhein and emodin in human renal tubular epithelial cells (HK-2), discovering that both emodin and rhein induced the apoptosis of HK-2 cells, having significant cytotoxic effect and the cytotoxicity of emodin on HK-2 cells was stronger than Rhein.

Animal experiments and clinical application confirmed rhubarb has hepatoprotective and choleretic effect. However, under certain conditions, rhubarb may damage liver [47]. Wang [107] investigated the effect of total extracts from prepared rhubarb on normal and pathological animals within a high dose range, finding prepared rhubarb showed bidirectional effects in hepatoprotection and hepatotoxicity, which could protect liver in $\mathrm{CCl}_{4}$ injured chronic hepatic injury, but had a certain hepatotoxic effect to normal animals.
Besides, rhubarb is of reproduction toxicity. Wang [108] explored the abortion effect and mechanism induced by rhubarb extract. The result showed that rhubarb extract not only interfered the stability of pregnancy state in pregnant mice for its purgative activity, but also directly affected endometrial environment in early embryonic mice, resulting in abortion. Administrating rhubarb for 30 days induced a significant toxic effect on testis in adult rats by promoting interstitial cell apoptosis, affecting the synthesis of testosterone, reducing spermic formation, and the injury degree was dose-dependent [109].

\section{Conclusion and perspectives}

Rhubarb is one of the oldest and most frequently used herbal medicines in China, Korea, Japan, and other Asian countries. In this article, we summarize the active ingredients, pharmacological effects, functional mechanisms of rhubarb, as well as its clinical applications. There are about 200 compounds isolated from rhubarb, including anthraquinones, anthrones, stilbenes, flavonoids, acylglucosides, and pyrones. Most of the studies focused on exploring the bioactivities of anthraquinones. These constituents have shown extensive pharmacological activities, including cathartic, anticancer, hepatoprotective, anti-inflammatory, anti-microbial, analgesic effects and so on.

Pharmacological effects of rhubarb are extensive. In clinic, it is used to treat various diseases, such as constipation, acute pancreatitis, gastrointestinal bleeding, DN, CRF and so on. But rhubarb is not suitable for long-term using to avoid producing toxic and side effects. It is an important direction for the development of rhubarb that reducing its toxicity, through compatibility, processing, changing the dosage or administration route et al., to play a better therapeutic role.

Main active ingredients of rhubarb, rhein, emodin, chrysophanol and so on, have extensive pharmacological activities with low toxic and side effects, possessing good application prospects. At present, rhein is studied as a drug candidate to treat cancer. The potential anti-tumor mechanisms may block cell cycle, induce apoptosis and control metastasis. Some scholars are also committed to develop rhein as a new drug for diabetic nephropathy. Lindleyin whose pharmacological action is similar to aspirin, is expected to be developed as a new anti-inflammatory and analgesic drug. Developing and applying monomer compounds divided from rhubarb is another development direction of rhubarb.

\section{Abbreviations}

TCM: Traditional Chinese Medicine; ALT: alanine aminotransferase; AST: aspartate transaminase; LPS: lipopolysaccharide; MAO: monoamine oxidase; 
GSH-ST: glutathione S-transferase; a-SMA: alpha smooth muscle actin; P-gp: P-glycoprotein; AP: acute pancreatitis; TNF-a: tumor necrosis factor-a; IL-1ß: interleukin 1 $\beta$; IL-6: interleukin 6; TC: total cholesterol; LDL: low density lipoprotein; TG: triglyceride; CRF: chronic renal failure; TGF- $\beta$ : transforming growth factor- $\beta$; MMP: mitochondrial membrane potential; MCP: monocalcium phosphate; Cr: creatinine; UN: urea nitrogen; LTB4: leukotrienes B4; NF-kB: nuclear transcription factor-kappa B; MAPK: mitogen-activated protein kinase; PI3K: phosphatidylinositol 3 kinase.

\section{Authors' contributions}

Y-PT proposed the framework of this paper. AK and J-AD implemented the thought of this paper. Y-JC wrote this paper. Z-JP, JS Collated the references. All authors read and approved the final manuscript.

\section{Author details}

1 Jiangsu Collaborative Innovation Center of Chinese Medicinal Resources Industrialization, and Jiangsu Key Laboratory for High Technology Research of TCM Formulae, and National and Local Collaborative Engineering Center of Chinese Medicinal Resources Industrialization and Formulae Innovative Medicine, Nanjing University of Chinese Medicine, Nanjing 210023, Jiangsu, China. ${ }^{2}$ College of Pharmacy and Shaanxi Collaborative Innovation Center of Chinese Medicinal Resources Industrialization, Shaanxi University of Chinese Medicine, Xianyang 712046, China.

\section{Acknowledgements}

Not applicable.

\section{Competing interests}

The authors declare that they have no competing interests.

\section{Availability of data and materials}

All data generated or analyzed during this study are included in this published article.

\section{Consent for publication}

Not applicable.

\section{Ethics approval and consent to participate}

Not applicable.

\section{Funding}

National Basic Research Program of China (973 Program) (2011CB505300 2011CB505303), National Natural Science Foundation of China (81603258), 333 High-level Talents Training Project Funded by Jiangsu Province (BRA2016387), and the Priority Academic Program Development of Jiangsu Higher Education Institutions (PAPD).

\section{Publisher's Note}

Springer Nature remains neutral with regard to jurisdictional claims in published maps and institutional affiliations.

Received: 5 September 2017 Accepted: 14 December 2017 Published online: 28 December 2017

\section{References}

1. Hu YP, Wang L, Li Y. Application of molecular techniques in the research of germplasm resources of Rheum. Biotech Bull. 2010;12:64-8.

2. Barceloux DG. Rhubarb and oxalosis (Rheum species). Dis Mon. 2009;55:403-11.

3. Jiao D, Du SJ. Study on rhubarb. Shanghai: Shanghai Science and Technology Press; 2000. p. 273-307.

4. Wang L, Pan S. Adjuvant treatment with crude rhubarb for patients with acute organophosphorus pesticide poisoning: a meta-analysis of randomized controlled trials. Complement Ther Med. 2015;23:794-801.

5. Lu L, Li HQ, Fu DL, Zheng GQ, Fan JP. Rhubarb root and rhizomebased Chinese herbal prescriptions for acute ischemic stroke: a systematic review and meta-analysis. Complement Ther Med. 2014;22:1060-70.

6. Zhou Y, Wang L, Huang X, Li H, Xiong Y. Add-on effect of crude rhubarb to somatostatin for acute pancreatitis: a meta-analysis of randomized controlled trials. J Ethnopharmacol. 2016;194:495-505.

7. Wang H, Song H, Yue J, Li J, Hou YB, Deng JL. Rheum officinale (a Traditional Chinese Medicine) for chronic kidney disease. Cochrane Database Syst Rev. 2012;7:CD008000.

8. Zheng QX, Wu HF, Guo J, Nan HJ, Chen SL, Yang JS, Xu XD. Review of rhubarbs: chemistry and pharmacology. Chin Herbal Med. 2013;5:9-32.

9. Fu XS, Chen F, Liu XH, Xu H, Zhou YZ. Progress in research of chemical constituents and pharmacological actions of Rhubarb. Chin J New Drugs. 2011;20:1534-8.

10. Guan Q, Liang S, Wang Z, Yang Y, Wang S. 1 H NMR-based metabonomic analysis of the effect of optimized rhubarb aglycone on the plasma and urine metabolic fingerprints of focal cerebral ischemia-reperfusion rats. J Ethnopharmacol. 2014;154:65-75.

11. Ma LP, Zhao L, Hu HH, Qin YH, Bian YC, Jiang HD, Zhou H, Yu LS, Zeng S. Interaction of five anthraquinones from rhubarb with human organic anion transporter 1 (SLC22A6) and 3 (SLC22A8) and drug-drug interaction in rats. J Ethnopharmacol. 2014;153:864-71.

12. Gao LL. Studies on the chemical constituents and biological activity of Rheum tanguticum Maxim.et Balf., Rhenm officinale Bail. and Rheum palmatum L. Doctor, Graduate School of Peking Union Medical College, Beijing, China; 2012

13. Tan ZH, Shen YJ, Zhao JN, Li YH, Zhang J. Effects of rhein on the function of human mesangial cells in high glucose environment. Acta Pharm Sin. 2004;39:881-6.

14. Su J, Yin LP, Zhang X, Li BB, Liu L, Li H. Influence of rhein intervention on the expression of HGF and BMP7 in renal tissue of rats with chronical allograft nephropathy. Chin J Clin Pharmacol. 2011;16:1114-20.

15. Wang WY, Zhao Y, Liu XD, Feng YJ, Suo W, Hang G. Preparation of rhein solid dispersion and its effects on experimental diabetic nephropathy in rats. West Chin J Pharm Sci. 2012;27:32-5.

16. Liu QY, Yu SJ. Effects of Rhein on resistin $m$ RNA expression of adipose tissue and plasma free fatty acid in diabetic obese rats. Chin J Tradit Chin Med Pharm. 2009;19:1061-3.

17. Ji YS. Pharmacology and application of active ingredients of Traditional Chinese Medicine. Beijing: People's Medical Publishing House; 2011. p. 95-117.

18. Cui Y, Lu P, Song G, Liu Q, Zhu D, Liu X. Involvement of PI3K/Akt, ERK and p38 signaling pathways in emodin-mediated extrinsic and intrinsic human hepatoblastoma cell apoptosis. Food Chem Toxicol. 2016;92:26-37.

19. Li L, Song X, Yin Z, Jia R, Li Z, Zhou X, Zou YF, Li LX, Yin LZ, Yue GZ, Ye G, Lv C, Shi WJ, Fu YP. The antibacterial activity and action mechanism of emodin from Polygonum cuspidatum against Haemophilus parasuis in vitro. Microbiol Res. 2016;186-187:139-45.

20. Brkanac SR, Geric M, Gajski G, Vujcic V, Garaj-Vrhovac V, Kremer D, Domijan AM. Toxicity and antioxidant capacity of Frangula alnus Mill. bark and its active component emodin. Regul Toxicol Pharmacol. 2015;73:923-9.

21. Chen YK, Xu YK, Zhang H, Yin JT, Fan X, Liu DD, Fu HY, Wan B. Emodin alleviates jejunum injury in rats with sepsis by inhibiting inflammation response. Biomed Pharmacother. 2016;84:1001-7.

22. Zhao YM, Fang YL, Li JC, Duan YX, Zhao HH, Gao L, Luo YM. Neuroprotective effects of Chrysophanol against inflammation in middle cerebral artery occlusion mice. Neurosci Lett. 2016;630:16-22.

23. Tong $Y$, Jin Z. Research progress of pharmacological effect of physcion. Chin Arch Tradit Chin Med. 2015;33:938-40.

24. Chen X, Gao H, Han Y, Ye J, Xie J, Wang C. Physcion induces mitochondria-driven apoptosis in colorectal cancer cells via downregulating EMMPRIN. Eur J Pharmacol. 2015;764:124-33.

25. Tabolacci C, Cordella M, Turcano L, Rossi S, Lentini A, Mariotti S, Nisini R, Sette G, Eramo A, Piredda L, Maria RD, Facchiano F, Beninati S. Aloe-emodin exerts a potent anticancer and immunomodulatory activity on BRAF-mutated human melanoma cells. Eur J Pharmacol. 2015;762:283-92.

26. Duval J, Pecher V, Poujol M, Lesellier E. Research advances for the extraction, analysis and uses of anthraquinones: a review. Ind Crops Prod. 2016;94:812-33. 
27. Li HL, Wang AB, Huang Y, Liu DP, Wei C, Williams GM, Zhang CN, Liu G, Liu YQ, Hao DL, Hui RT, Lin M, Liang CC. Isorhapontigenin, a new resveratrol analog, attenuates cardiac hypertrophy via blocking signaling transduction pathways. Free Radic Biol Med. 2005;38:243-57.

28. Dai WS, Zhao RH, Chen HB. Content determination of tannins in Rheum officinale by Casein method. Lishizhen Med Mater Med Res. 2003;14:324-6.

29. Zhong HY, Zhang M, Dai Y, Zhang HF. Effect of tannin contained in Radix et Rhizoma Rhei and Radix Polygoni Multiflori on small intestinal propulsion. Lishizhen Med Mater Med Res. 2006;17:2478-9.

30. Shahid A, Ali R, Ali N, Hasan SK, Bernwal P, Afzal SM, Vafa A, Sultana S. Modulatory effects of catechin hydrate against genotoxicity, oxidative stress, inflammation and apoptosis induced by benzo(a) pyrene in mice. Food Chem Toxicol. 2016;92:64-74

31. Zeng LN, Ma ZJ, Zhao YL, Zhang LD, Li RS, Wang JB, Zhang P, Yan D, Li $Q$, Jiang $B Q, P u S B$, Lu Y, Xiao XH. The protective and toxic effects of rhubarb tannins and anthraquinones in treating hexavalent chromium-injured rats: the Yin/Yang actions of rhubarb. J Hazard Mater. 2013;246-247:1-9.

32. Nan HJ, Xu XD, Chen SL, Bai ZC. Research progress in Rheum plants. Nat Prod Res Dev. 2009;21:690-701.

33. Lei S. Bioactivities, isolation and purification methods of polysaccharides from natural products: a review. Int J Biol Macromol. 2016;92:37-48.

34. Xie Y, Li GW, Ma YM. Research progress in rhubarb polysaccharides. Chin J New Drugs. 2010;19:755-8.

35. Li H, Wang J, Qu Y, Xiao X. Analysis on changes of purgative biopotency in different processed products of rhubarb. Chin J Chin Mater Med. 2012:37:302-4.

36. Takayama K, Tsutsumi H, Ishizu T, Okamura N. The influence of rhein 8-O- $\beta$-D-glucopyranoside on the purgative action of sennoside A from rhubarb in mice. Biol Pharm Bull. 2012;35:2204-8.

37. Feng $T S$, Yuan ZY, Yang RQ, Zhao S, Lei F, Xiao XY, Xing DM, Wang WH, Ding Y, Du LJ. Purgative components in rhubarbs: adrenergic receptor inhibitors linked with glucose carriers. Fitoterapia. 2013;91:236-46.

38. Qu Y, Wang JB, Li HF, Wang Q, Xiao XH, He YZ. Study on relationship of laxative potency and anthraquinones content traditional Chinese drugs containing. Chin J Chin Mater Med. 2008;33:806-8.

39. Kon R, Ikarashi N, Nagoya C, Takayama T, Kusunoki Y, Ishii M, Ueda H, Ochiai W, Machida Y, Sugita K, Sugiyama K. Rheinanthrone, a metabolite of sennoside A, triggers macrophage activation to decrease aquaporin-3 expression in the colon, causing the laxative effect of rhubarb extract. J Ethnopharmacol. 2014;152:190-200.

40. Nie K. Research and thinking on pharmacological action of rhubarb. ShanDong Univ Trad Chin Med. 2009;33:239-62.

41. Lemmens $L$, Borja $E$. The influence of dihydroxyanthracene derivatives on water and electrolyte movement in rat colon. J Pharm Pharm. 1976;28:498-501.

42. Wang XW, Liu HF, Xu M. Effect of rhubarb on changes of cholinergic nerves in colonic myenteric plexus for chronic slow transit constipation rat. Chongqing Med. 2008;37:1685-7.

43. Zhang WS, Li F, Bao JQ, Wang SC, Shang GW, Li JC, Wang CH. Regulatory effect of anthraquinone derivatives from rhubarb on Aquaporin 4 expression in colon of rats and in LoVo cell line. Chin J Integr Trad West Med. 2008:28:818-23.

44. Li GF. Analysis on pharmacological effects and clinical application of rhubarb. Guide Chin Med. 2013;16:317-8

45. Li F, Wang SC, Wang X, Ren QY, Wang W, Shang GW, Zhang L, Zhang SH. Novel exploration of cathartic pharmacology induced by rhubarb. Chin J chin mater med. 2006:4:481-4.

46. Qin LS, Zhao HP, Zhao YL, Ma ZJ. Protection and bidirectional effect of rhubarb anthraquinone and tannins for rats liver. Chin J Integr Trad West Med. 2014;34:698-703

47. Qiu H, Mao DW, Wei AL. Preventive and therapeutic effects of rhubarb extract on hepatic encephalopathy in rats with acute hepatic failure. Chin Med Mat. 2002;25:573-5.

48. Zhang LL, Zhang HY, Wang LM, Li XJ, Jia JT, Lv ML, Fan YM, Zhang CY, Liu MS, Zhao ZF, Han DW, Cheng J. Protective effect of emodin on lung injury induced by hepatic fibrosis in rats. Chin J Pathophys. 2014:30:291-6.
49. Wang $X L$, Zhang YB, Li XY, Niu YC, Qi YQ, Zhu LQ, Dong MX. Effects of emodin on hepatic fibrosis in rats and underlying mechanisms. Chin Med Pharmaco Clinic. 2013:4:56-8.

50. Xiong XL, Yan SQ, Qin H, Zhou LS, Zhang LL, Jiang ZX, Ding Y. Protective effect of emodin pretreatment in young rats with intrahepatic cholestasis. Chin J Contemp Pediatr. 2016;18:165-71.

51. Sui F, Yan MJ, Li Y. L N, Xiao YQ, Li L. Comparison of the actions on blood stasis of rhubarb with different prepared methods. Chin Med Pharmaco Clinic. 2012;6:90-3.

52. Wang RQ. Clinical observation of the treatment of micron rhubarb charcoal in peptic ulcer bleeding and the mechanism of platelet system. Master, Hubei College of Traditional Chinese Medicine, Hubei, China; 2007.

53. Zhang S, Shi ZH, Hao JJ, Wang RQ. Hemostatic mechanism of micron rhubarb charcoal. J Chengdu University Trad Chin Med. 2007;30:54-5.

54. Wang GD, Yan T. Clinical application and research of rhubarb. Sichuan: Sichuan Science and Technology Press; 2013.

55. Wang ZW, Guo M, Ma D, Wang RJ. Effects of rhubarbs from different regions on blood lipid and antioxidation of hyperlipidemia rats. Chin J Appl Physiol. 2015;31:278-81.

56. Wang YM, Tian LH, Zhang J. Effects of rhubarb polysaccharide on blood glucose, blood lipids, hepatic lipase activity in rats with diabetic atherosclerosis. Mod Med J Chin. 2008;10:6-9.

57. Zhou SP, Zhou LL, Han W, Wu HP, Li H. Regulating effect of emodin on lipid metabolism and plasma fibrinogen in hyperlipidemic model. Chin J Trad Med Sci Tech. 2007:14:349-50.

58. Du L, Yuan B, Zhang BX, Zhang YL, Gao XY, Wang Y. Study on mechanism for anti-hyperlipidemia efficacy of rhubarb through assistant analysis systems for acting mechanisms of Traditional Chinese medicine. Chin J Chin Mater Med. 2015;40:3703-8.

59. Chen K, Wang CQ, Fan YQ, Han ZH, Wang Y, Gao L, Zeng HS. Lipid-lowering effect of seven traditional Chinese medicine monomers in zebrafish system. Sheng Li Xue Bao. 2017;69:55-60.

60. Wu YX. Clinical application of Dahuang in the treatment of diabetic nephropathy. Clin J Chin Med. 2013;5:29-30.

61. Bi LM. The Research about the effects of fluvastatin and emodin on the expression of MCP-1 on diabetic kidney rats. Master, Nanjing University of Chinese Medicine, Jiangsu, China; 2007.

62. Peng LL. Integrin-linked kinase regulates the ratio of MMP-9/TIMP-1 in tubular epithelial Myofibroblast transdifferentiation of diabetic nephropathy and the role of rhein. Doctor, Central South University, Hunan, China; 2012.

63. Ai ZH, Cai HW, Zhong ZH. Therapeutic effects of rhein on experimental diabetic nephropathy in rats. Acta Acad Med Mil Tert. 2004;26:304-6.

64. Gu LB, Wan YG, Wang M. Advances in molecular mechanism of rhubarb in the treatment of diabetic nephropathy. Chin J Chin Mater Med. 2003;28:703-5.

65. Wang M. Protective effect of rhein on kidney in obese diabetic rats and its mechanism. Doctor, Liaoning University of TCM, Liaoning, China; 2008.

66. Qi ZQ, Hu HZ, Wang XS, Li W. Review on molecular and cellular mechanism researches of emodin for treating kidney disease. Global Chin Med. 2015;9:1145-8.

67. Li Y, Yan MJ, Sui F, Lin N, Liu LL, Xiao YQ, Li L, Ma CY. Study on antipyretic effect and mechanism of alcohol extracts from different processed rhubarb. J Chin Med Mater. 2012;35:1224-7.

68. Yan J. Study on neuroprotective effects and mechanism of chrysophanol liposomes on cerebral ischemia-reperfusion injured mice. Doctor, Hebei Med University, Hebei, China; 2014.

69. Zhang M. The laboratory investigation of the effects on emodin and chrysophanol to hypoxic damaged neural cell. Master, Lanzhou University, Gansu, China; 2010.

70. Lin $M X, W u$ J, Zhuang R, Wang BJ, Jin SW. Influence of rhubarb combined shenfu injection on respiratory functions of acute respiratory distress syndrome patients. Chin Arch Tradit Chin Med. 2013:6:1465-7.

71. Wang ZW, Guo M, Ma D, Tuo HY, Wang RQ. Analysis of anti-inflammatory effect and mechanism of Rheum tanguticum cultivated in South of Gansu. Chin J Exp Tradit Med Form. 2016;22:158-61. 
72. Du JD, Yu ZH, He FD. Effect of emodin on the expression of osteocalcin and interleukin-6 in periodontal tissues of periodontitis rats. Clin Med. 2009;29:92-5

73. Jang YN, Mo HY, Ren H. Effect of emodin lipid nano-microbubble on MAPK signal pathway and inflammation cytokine in AT-II cells by mechanical stretch. Chin Med Mat. 2013;36:967-71.

74. Huang M, Ma J, Yang CH, Lu B, Guo P, Shao JQ, Du H, Wang J. Effects of rheinic acid on markers of insulin secretion, inflammation and oxidative injury in db/db mice. Chin Remed Clin. 2013;13:976-9.

75. Hu B, Zhang H, Meng X, Wang F, Wang P. Aloe-emodin from rhubarb (Rheum rhabarbarum) inhibits lipopolysaccharide-induced inflammatory responses in RAW264.7 macrophages. J Ethnopharmacol. 2014;153:846-53.

76. Lin SZ. Study on the effects of emodin on pancreatic cancer and its mechanisms. Doctor, Zhejiang University, Zhejiang, China; 2011.

77. Wang RT, Yin H, Dong SB, Yuan W, Liu YP, Liu C. Research progress of emodin anti-gallbladder carcinoma. Chin J Chin Mater Med. 2014;39:1976-8.

78. Li RF, Yang FJ, Zhao J, Ye YT, Xu WQ. Effects of dihydroxy anthraquinones compound on radiosensitivity of cervical carcinoma HeLa cells. Chin Pharm. 2011;15:1353-6.

79. Liu A, Deng ZF, Hu JX, Han SW, Huang LL, Ke PY, Lin SZ. Effect of emodin on cell proliferation and apoptosis of human pancreatic cancer cell line Panc-1. Chin Tradit Herbal Drugs. 2011;42:756-9.

80. He ZH, He MF, Ma SC, But PP. Anti-angiogenic effects of rhubarb and its anthraquinone derivatives. J Ethnopharmacol. 2009;121:313-7.

81. Tsai KH, Hsien HH, Chen LM, Ting WJ, Yang YS, Kuo CH, Tsai CH, Tsa FJ, Tsai HJ, Huang CY. Rhubarb inhibits hepatocellular carcinoma cell metastasis via GSK-3-beta activation to enhance protein degradation and attenuate nuclear translocation of beta-catenin. Food Chem. 2013:138:278-85.

82. Li CL, Ye YW, Sun JY. Study on antimicrobial activity of emodin and aloeemodin. Chin J Pharmacol Toxicity. 1989:5:381-1234.

83. Tian B, Hua YJ, Ma XQ, Wang GL. Relationship between antibacterial activity of aloe and its anthaquinone compounds. Chin J Chin Mater Med. 2003;28:1034-7.

84. Zhou L, Yun BY, Wang YJ, Xie MJ. Antibacterial mechanism of emodin on Staphylococcus aureus. Chin J Biochem Mol Biol. 2011;27:1156-60.

85. Liu M. Investigation on its Anti-MRSA effects of emodin in vitro and in vivo, and its mechanism. Doctor, Third Military Medical University, Chongqing, China; 2015.

86. Li J, Yin LB, Zhang X, Li BB, Liu L, Li H. Influence of rhein intervention on the expression of HGF and BMP7 in renal tissue of rats with chronical allograft nephropathy. Chin J Clin Pharm Therap. 2011;16:1114-20.

87. Liu LJ, Qian H, Zhang P. Protective effect of emodin on rats with pulmonary fibrosis and its partial mechanisms. Chin Pharmacol Bull. 2015;31:266-72.

88. Xu K, Zhang L. Research progress of rhein acid on renal fibrosis. J New Chin Med. 2012:44:119-21.

89. Gu QP, Liu JJ, Xie JF. Clinical observation on 100 cases of chronic constipation treated by rhubarb combined with Lactobacillus in Elderly. Strait Pharm J. 2015;27:118-9.

90. Luo HQ, Lin XJ, Liu XM. Clinical effect and nursing of hot compress with fructus evodiae and coarse salt combined with acupoint sticking of rhubarb in prevention of constipation after stroke. Zhong Xi Yi Jie He Hu Li. 2015;1:4-8.
91. Liu SX, Zhao CZ, Yang DD. Clinical study on umbilical area applying rhubarb and borneol to prevent constipation for acute myocardial infarction patients. Hu Li Yan Jiu. 2010;24:881-2.

92. Yu XF. Observation of clinical efficacy on constipation after orthopedic surgery treated with umbilicus compress of rhubarb and mirabilite in the patients. Shi Jie Zhong Xi Yi Jie He Za Zhi. 2014;6:614-6.

93. Zhu W, Wang XM. Progress in study on mechanisms of rhubarb in treating chronic renal failure. Chin J Integr Trad West Med. 2005;25:471-5.

94. Liu HF, Zhang CY. Comprehensive nursing rhubarb compound enema decoction high colon dialysis treatment for diabetic nephropathy phase IV and V clinical observation. Hu Li Tian Di. 2016;1:184-6.

95. Xiong ZH. The study of intervention effect and molecular mechanism of rhubarb used in diabetic nephropathy. Doctor, Guangzhou University of Chinese Medicine. Guangzhou, China; 2012.

96. Wang JN. Clinical observation of the combined treatment of rhubarb soda and jinshuibao capsule on chronic renal failure. Chin J Clin Rational Drug Use. 2013;6:67-8.

97. Xiao W, Deng HZ, Ma Y. Summarization of the clinical and laboratory study on the rhubarb in treating chronic renal failure. Chin J Chin Mater Med. 2002;27:241-4.

98. Sun BQ, Zhu GB. Clinical observation on treatment of rhubarb and mirabilite on severe acute pancreatitis. J Emerg Tradit Chin Med. 2017;23:1155-6.

99. Zhang Y, Wang P, Yang YM, Zang Y, Yu YP, Meng XL, Chen XR. Protective effect of rhubarb free Anthraquinone on intestinal barrier injury in beagle dogs induced by severe acute pancreatitis. Chin J Exp Tradit Med Form. 2013:19:172-6.

100. Wang $L L$, Liu $Y Q$, Cheng $L$, Fan $L$, Xiong $Y X$. The influence of free anthraquinone of rhubarb in sever acute pancreatitis induced kidney injury. Chin Med Pharmaco Clin. 2015;31:31-4.

101. Wang SZ. Forty cases with UPPer gastrointestinal hemorrhage treated with oral administration of raw dahuang powder. Henan Trad Chin Med. 2015:35:2798-9.

102. Liao SF, Chen HM, Zhang YQ, Wang YC. Clinical study on controlling upper gastrointestinal bleeding by early nasogastric feeding rhubarb powder after severe brain injuries. Mod Med J China. 2004;14:105-7.

103. Guo P, Zhang TJ, Zhu XY, He YZ. Study on toxicity of Radix et Rhizoma Rhei and countermeasure for its attenuation. Chin Tradit Herbal Drugs. 2009;40:1671-4.

104. Du C, Wang CL, Fan BL. Advances in research on target organ of rhubarb and its specific toxicity. J Toxicol. 2015;29:461-4.

105. Yan M, Zhang LY, Sun LX, Jiang ZZ, Xiao XH. Nephrotoxicity study of total rhubarb anthraquinones on Sprague Dawley rats using DNA microarrays. J Ethnopharmacol. 2006;107:08-11.

106. Wang QX. Study on the toxicity and its mechanism of rhubarb and its major constituents. Doctor, Academy of Military Medical Sciences, Beijing, China; 2007

107. Wang YH, Zhao HP, Wang JB, Zhao YL, Xiao XH. Study on dosage-toxicity/efficacy relationship of prepared rhubarb on basis of symptombased prescription theory. Chin J Chin Mater Med. 2014;39:918-23.

108. Wang HF, Guo B, Ma XP, Xue RC. Reproductive toxicity study of rhubarb extract on early pregnancy mice and its preliminary mechanism. Chin $J$ Immun. 2016:32:184-8.

109. Hu XC. Study on the reproductive toxicity of rhubarb in male rats. Master, Chengde Medical College, Hebei, China, 2012. 